\title{
GCU
}

Glasgow Caledonian

University

University for the Common Good

\section{Valuing QALYS at the end of life}

Pinto Prades, Jose Luis; Sánchez-Martínez, Fernando-Ignacio; Corbacho, Belen; Baker, Rachel

Published in:

Social Science and Medicine

DOI:

10.1016/j.socscimed.2014.04.039

Publication date:

2014

Document Version

Author accepted manuscript

Link to publication in ResearchOnline

Citation for published version (Harvard):

Pinto Prades, JL, Sánchez-Martínez, F-I, Corbacho, B \& Baker, R 2014, 'Valuing QALYS at the end of life', Social Science and Medicine, vol. 113, pp. 5-14. https://doi.org/10.1016/j.socscimed.2014.04.039

\section{General rights}

Copyright and moral rights for the publications made accessible in the public portal are retained by the authors and/or other copyright owners and it is a condition of accessing publications that users recognise and abide by the legal requirements associated with these rights.

Take down policy

If you believe that this document breaches copyright please view our takedown policy at https://edshare.gcu.ac.uk/id/eprint/5179 for details of how to contact us. 


\section{Authors' final copy:}

Jose-Luis Pinto-Prades, Fernando-Ignacio Sánchez-Martínez, Belen Corbacho, Rachel Baker (2014)

Valuing QALYS at the End of Life Social Science \& Medicine 113: 5-14

\section{a. Abstract}

The relative value of QALYs, benefiting different patient groups in different ways (for example by extending life or improving quality of life), has been a source of debate. Most recently, the relative value of QALYs at the end of life (EoL) has been a focus of research and policy. The objective of this study is to provide evidence of societal preferences in relation to the relative value of QALYs gained at the EoL. Three cross-sectional surveys were conducted amongst Spanish general population $(n=813)$. Survey 1 compared increases in life expectancy for EoL patients with health gains from temporary health problems. Survey 2 compared health gains for temporary health problems with quality of life gains at the EoL (palliative care). Survey 3 compared increases in life expectancy with quality of life gains, both for EoL patients. Preferences were elicited using Person Trade-Off (PTO) and Willingness to pay (WTP) techniques presenting two different durations of health benefit (6 and 18 months). Health benefits, measured in QALYs, were held constant in all comparisons.

In survey 1 mean WTP was higher for life extending treatments than for temporary health problems and the majority of respondents prioritised life extension over temporary health problems in response to the PTO questions. In survey 2 mean WTP was higher for palliative care than for temporary health problems and $83 \%$ prioritized palliative care (for both durations) in the PTO questions. In survey 3 WTP values were higher for palliative care than for life extending treatments and more than $60 \%$ prioritized palliative care in the PTO questions. Our results suggest that QALYs gained from EoL treatments have a higher social value than QALYs gained from treatments for temporary health problems. Further, we found that people attach greater weight to improvements in quality of life than to life extension at the end of life. 


\section{Introduction}

The issue of 'QALY weights', debated in the health economics and health policy literature for some time, has seen renewed interest recently. One of the reasons for this is the decision by the UK government to introduce Value-Based Pricing for medicines in 2014. In their response to a consultation about value based pricing, the UK Department of Health, Pharmacy \& Industry Group (2011) stated that "QALY measures may not capture all aspects of the value society gains from new treatments...The Government is proposing to calculate 'QALY weights'" (p.24). One example of the introduction of QALY weights in the UK has been End-of-Life treatments. In a public consultation about the value of End of Life (EoL) medicines, the National Institute for Health and Care Excellence (NICE, 2008) asked if it should "place additional weight on proven survival benefits in patients with terminal illness and short life expectancy". A significant majority (63\%) of those who responded to the consultation document backed this proposal. Following this consultation, NICE (2009) established that, if medicines fulfil certain criteria they will be regarded as "end of life" and the Appraisal Committee will consider "the impact of giving greater weight to QALYs achieved in the later stages of terminal diseases" and "the magnitude of the additional weight". NICE policies have international significance as other countries make reference to pharmaceutical pricing and heath technology appraisal in the UK. For example, the UK Office for Fair Trading (OFT, 2007) estimates that, although the UK represents only a small proportion of total pharmaceutical sales, countries representing $25 \%$ of global pharmaceutical sales reference UK prices.

There has been much debate about the potential for applying a positive weight to the value of QALYS in the case of EoL treatments (Institute of Medicine (IOM), 2009; Maynard \& Bloor, 2009; Raftery, 2009; Towse, 2009;). Most of the arguments are based on normative judgments but there is some empirical evidence. A few papers (Morris \& Perez, 2000; Nadler, Broderick, Zarotsky, \& Kim, 2009; Nadler, Eckert, \& Neumann, 2006) estimated health professionals' Willingness to Pay (WTP) for life extending cancer treatments and found an implicit monetary value of a QALY higher than $\$ 150,000$. This implies that there may be willingness to pay a premium for these treatments. There are three studies that have estimated preferences amongst the general population. Two large web-based surveys $(n=4118$ and $n=4008$ ) have been conducted in the UK (Linley \& Hughes, 2012; Shah, Tsuchiya, Hole, \& Wailoo, 2012) and, on average, they did not find overall support for giving extra weight to EoL treatments. The EuroVaQ project (Donaldson, 2010) was funded by the European 
Commission to derive a monetary value of a QALY. A total of 17,657 subjects, across ten countries, responded to a web-based WTP survey and findings suggest that there is more value attached to life extension in the case of terminal illness, than for other types of QALY gains.

Given the pervasive influence of framing effects and the differences in study designs, the explanation for this discrepancy may not be straightforward. For example, both UK studies adopted a "social" perspective while the EuroVaQ study framed questions from an individual perspective. In the UK surveys subjects were asked to choose between patients with different characteristics, between different sized groups of patients or they were asked to state how they would like NHS money to be spent. EuroVaQ respondents were making hypothetical decisions about how to spend their own money, since questions were about WTP for own health. Another important distinction between the UK studies and EuroVaQ is that the UK studies presented choices between EoL situations and scenarios which could be regarded as "almost" EoL. For example, a health gain for somebody with an 18 months life expectancy versus a health gain of somebody else with 60 months life expectancy. Whilst a life expectancy of 60 months may not be considered EoL by researchers or policy makers, many of the people surveyed would regard 5 years as very short, compared with their own life expectancy. In the EuroVaQ project the authors compared mean WTP for one QALY gained by extending life immediately (assuming imminent death), with mean WTP for one QALY gained by improving quality of life over a specified number of life years (25\% increase in QoL for 4 years and $10 \%$ for 10 years). None of the three general population studies investigated preferences for quality of life versus life extension for people at the EoL. In summary, whilst there is some evidence of societal values in relation EoL treatments, there are a number of outstanding issues around the justification (or not) for a premium for EoL treatments.

This paper will address the following questions in order to shed light on some of the issues mentioned:

1. Are treatments that extend life at the EoL valued more than treatments that improve quality of life for temporary health problems?

2. Are treatments that improve quality of life at the EoL valued more than treatments that improve quality of life for temporary health problems? That is, do EoL treatments have more social value than treatments for temporary problems even if they do not extend life?

3. Do people discriminate between different ways of obtaining QALYs (gains in life expectancy versus 
gains in quality of life) within EoL treatments?

This paper presents the results of three surveys that were designed to investigate the above questions. The results indicate that members of the general population attach additional value to health gains resulting from EoL treatments. Respondents also seem to attach a greater value to palliative care than to life extension at the end of life.

\section{Methods}

\subsection{Surveys}

Three surveys were conducted using Computer Assisted Personal Interviews (CAPI). Survey 1 $(n=240)$ presented respondents with hypothetical health gains achieved through improvements in quality of life via treatment for a temporary condition (T-QoL) as well as health gains achieved through improvements in life expectancy at the end of life (EoL-LE). Survey $2(n=232)$ compared the temporary health gains (T-QoL) used in Survey 1 with health gains at the end of life achieved by improving quality of life (EoL-QoL), via palliative care. In Survey 2, both treatments only improved quality of life without affecting life expectancy. Survey $3(n=348)$ included the two EoL scenarios used in Surveys 1 and 2 in order to directly compare the two EoL treatments (EoL-LE vs. EoL-QoL). It could be thought that these two treatments were already being compared, as in Surveys 1 and 2 they were both compared with T-QoL. However, there is psychological evidence (Loomes, 2010; Shafir, Osherson, \& Smith, 1989) showing that comparing two objects A and B indirectly by means of a third object $\mathrm{C}$ is not always the same as comparing $\mathrm{A}$ and $\mathrm{B}$ directly.

\subsection{Scenarios}

Six different scenarios were used in the survey (Table 1) corresponding to three types of health gains (Temporary, Life Extending, and Palliative); and two different durations of benefits (6 and 18 months). Figure 1 shows diagrammatically the health gains involved in each of the scenarios. Different durations were used for two reasons. Firstly, to test if the potential weight for EoL treatments changed with the size of the health gain. For example, some people may give a relatively higher value to extending life as the gain increases. Secondly, to test the consistency of responses, e.g. whether WTP is higher for larger health gains than for smaller health gains. Quality of life was presented as a "percentage" and respondents were told that $100 \%$ was normal health for somebody of his/her age and $0 \%$ a very bad condition, as bad as death. This way of presenting quality of life has been applied in previous studies (Shah, et al., 2012; Dolan \& Tsuchiya, 2009). 


\section{[INSERT FIGURE 1 ABOUT HERE]}

\section{[INSERT TABLE 1 ABOUT HERE]}

\subsection{Elicitation procedures}

Two types of question were asked in order to elicit preferences: WTP and Person Trade-Off (PTO). WTP is well grounded in Welfare Economics and is used to inform regulatory or investment decisions in non-health divisions of the public sector. However, WTP has been criticized as a measure of preference in a public health system (Culyer et al., 2007). It is argued that since a public health system has a fixed budget, the relevant issue is not how much subjects are WTP but the opportunity costs of funding new treatments. Moreover social decisions incorporate an equity element that is absent in WTP. For this reason, PTO has been proposed as an alternative method to elicit preferences in the health care sector (Nord, Pinto, Richardson, Menzel, \& Ubel, 1999). By using both methods we examine whether different perspectives (individual vs social) elicit different preferences for EoL treatments.

The WTP questions asked individuals to imagine an illness and a treatment for that illness which increases the chances of improving their condition by $10 \%$. The wording was as follows (for scenario 1):

"Imagine that you are diagnosed with a very severe illness. Doctors tell you that in a few days your health state will deteriorate and your health related quality of life will be $50 \%$ (remember that 100\% health is the health state of somebody without health problems) for 3 months. After these months you would die. That is, it is a terminal illness.

The doctor tells you that there is a treatment which might extend your life for 6 additional months with the same health related quality of life of 50\%. This treatment only works in $10 \%$ of patients (10 out of 100 patients). For this reason, 90 out of 100 will not improve at all and their life expectancy would remain at 3 months."

A low probability of improvement was used for two reasons. One was to reduce the anxiety that a $100 \%$ chance of recovery could generate especially in the case of EoL-LE treatments. In piloting, interviewers suggested that some subjects had problems with this question as it sounded like "pay or die". The second reason was that a $100 \%$ chance of success would imply very large health gains (e.g. almost 1 QALY in the case of the 18 months duration) and such large health gains may mean that some respondents are faced with budget constraint problems in WTP questions, resulting in insensitivities in WTP responses. In Scenarios 1,3 and 5 the health gain was exactly the same (see 
Figure 1) and equivalent to 0.025 QALYs while in Scenarios 2, 4 and 6 it was 0.075 QALYs. All the scenarios were illustrated using visual aids such as those in Figures 2 and 3.

\section{[INSERT FIGURE 2 ABOUT HERE]}

\section{[INSERT FIGURE 3 ABOUT HERE]}

In order to elicit WTP, (for individuals who stated they would pay a small amount (5 euros) for the treatment, a table containing a very wide range of sums of money was used $(5,10,20,50,100,200$, $300,500,700,1000,1500,2000,2500,3000,4000,5000,7000,10000,25,000$, and more than 25,000 euros). Respondents were presented with these amounts of money simultaneously, on the computer screen. They were asked to state if they would pay each of these amounts or not. This produced an interval and respondents were then asked to state their maximum WTP within the interval (or above 25,000 euros if they stated yes to all).

In the PTO questions the health gains were the same than those used in the WTP questions. Respondents were asked to choose between two patients (A or B) described in terms of the type of health gain. An example of this type of questions is the following (scenario 5 vs. scenario 1):

"Imagine there are two patients, $A$ and $B$. Patient $A$ has been diagnosed with a disease and s/he is told that s/he will spend the next six months with a quality of life of $30 \%$ (remember that $100 \%$ health is the health state of somebody without health problems). There is a treatment for this disease so after 6 months (more or less) s/he will be back to $100 \%$. However, this treatment does not relieve symptoms. So until s/he recovers (about 6 months) s/he will experience a quality of life of $30 \%$. The illness is not life threatening. It is, therefore, a temporary health problem.

Patient $B$ has been diagnosed with a terminal health problem. In a few days, his/her health will deteriorate and s/he will have a health state that is 50\% of full health. Once this happens (almost immediately) her life expectancy will be about 3 months.

There are medical treatments that may improve the health of both patients. In the case of patient $A$, there is a treatment that can alleviate symptom during these 6 months that she needs to recover completely. This treatment can improve his/her health up to $80 \%$, that is, it improves health but it is not perfect. In the case of patient $B$, there is a treatment that will improve his/her life expectancy by 6 months, that is life expectancy increases from 3 to 9 months.

Assume that there is not enough money to provide treatment to both patients and we can only help one of them. If you were the person that had to decide to choose between patient A or patient $B$, who would you choose?

If the respondent chose patient $A$, the next question presented a choice between two patients like $B$ or one patient like $\mathrm{A}$. If they still preferred $1 \mathrm{~A}$ to $2 \mathrm{~B}$, a table with an increasing number of $\mathrm{B}$ 's, $(3,4,5$, 
$10,15,20,30,50,100,5000,1000$, and more than 1000) similar to the table used in WTP questions, was presented to the respondent. In a similar fashion to the WTP table, respondents were asked to choose between one patient $A$ and each of the numbers of patient $B$, thus producing an interval where the respondent's point of indifference between A and B was located. The subject was asked to state the number of patients of one type that was equivalent to 1 patient of their more preferred type. Notice that whilst risk is a feature of the WTP questions, it is not part of the PTO questions, for several reasons. Firstly there are no personal budgetary restrictions in PTO. Secondly, in piloting we did not observe the same problems that had been observed with WTP. While subjects seemed to have problem with the idea of paying for delaying certain death they accepted the idea of choosing between two patients. Lastly, we can compare preferences elicited with these two methods providing we make ordinal comparisons since utility functions and value functions produce the same ordinal ranking of goods (Keeney \& Raiffa, 1976).

\subsection{Structure of the questionnaires}

The three surveys had a similar structure (see Table 2). Each began with a short description of the background to the study and an explanation of the concept of quality of life, which was presented as a percentage. After this introduction, the questionnaires were comprised of two WTP questions, followed by two PTO questions, and two more WTP questions. The preference elicitation questions were ordered in this way in an attempt to reduce anchoring effects observed in the literature on WTP (Simonson \& Drolet, 2004). At the end of the questionnaire, there was a series of socio-demographic questions and a final question about the degree of difficulty of the survey (from 1 to 5).

\section{[INSERT TABLE 2 ABOUT HERE]}

\subsection{Piloting and data collection}

Extensive piloting preceded the main phase of data collection. After some informal piloting with colleagues and university staff, a face-to-face pilot study $(n=120)$ using a printed questionnaire was conducted to a convenience sample of the public by the company that conducted the final survey. We made some changes to the survey after the pilot. The main one was the need to frame WTP in probabilistic terms. Some other minor modifications were made to the visual aids. Following the pilot survey the three surveys were conducted using a face-to-face computer-assisted personal interview (CAPI). The surveys took place in the South of Spain (provinces of Malaga, Seville and Murcia) over a period of six months (May to November, 2010). The duration of the interviews was 21 minutes on 
average.

In order to generate a quota-sample, representative of the population of Spain in terms of age and sex, 40 census areas were chosen randomly from the three provinces. Within each area a starting point address was identified, again randomly. Interviewers then walked a 'random route' from this start point, with instructions about how to choose the dwellings and how to substitute those dwelling if access was not possible. If there were several people living at a particular address interviewers selected a respondent according to age and sex quotas.

\subsection{Data Analysis}

\subsubsection{PTO data}

PTO responses generate relative values. However, there is no single, preferred method to aggregate these relativities. We used two methods previously applied (Chilton et al, 2002; Baker et al., 2010) that have desirable theoretical properties. They are dubbed the "ratio of means" and the "median of ratios". We use an example (see Table 3) to explain how they are estimated.

\section{[INSERT TABLE 3 ABOUT HERE]}

Ratio of means.- We assigned a value of 1 to the most preferred type of patient and a value of $1 / N_{i}$ to the other patient, where $N_{i}$ is the number of patients of the least preferred type that are equivalent to 1 patient of the most preferred type. For example, if $1 \mathrm{~A}=10 \mathrm{~B}$ then $\mathrm{A}$ is the most preferred group, the value for $A$ is set to 1 and the value of $B$ is 0.1 . The average relative values for $A\left(R_{A}\right)$ and $B\left(R_{B}\right)$ are estimated (0.68 and 0.48 in Table 3 ) and the ratio of these averages is the aggregate measure of preference. There are two possible "ratio of means", namely, $\left(R_{A} / R_{B}\right)$ or $\left(R_{B} / R_{A}\right)$. This is arbitrary. In our example, they are 1.41 or 0.71 . They both imply that patient $A$ has a higher social weight than a patient $B$ and this weight is 1.41 (since $1 / 0.71=1.41$ ).

Median of ratios.- We assigned a value of 1 to the same option in all cases (either A or B) and set the relative value with reference to that option $(B / A$ if $A=1$ or $A / B$ if $B=1)$. The measure of the relative social value is just the median of anyone of those ratios. In the example of table 3 it would be 4 (if $A=1$ ) or 0.25 (if $B=1$ ). In both cases, the relative social value for $B$ is four times the value of $A$.

\subsubsection{WTP data}


The mean is the theoretically correct measure of central tendancy for the WTP responses. This is what it is usually reported in the literature and this is what we will report here as well. However, we also analysed WTP data using "ratio of means" and "median of ratios" methods. In this way WTP and PTO results can be compared more directly. For WTP data these methods were applied as follows: Ratio of means.-

If $W T P(A)>W T P(B)$, then $V(A)=1$ and $V(B)=W T P(B) / W T P(A)$. If $W T P(B)>W T P(A)$ then $V(B)=1$ and $V(A)=W T P(A) / W T P(B)$. If $W T P(A)=W T P(B)$ then $V(A)=V(B)=1$. Once $V(A)$ and $V(B)$ are calculated for each subject, the ratio of means is estimated as with PTO.

Median of ratios:

Firstly, $A$ or $B$ is chosen as the base. Assume it is $A$. Then $R(A)=W T P(B) \operatorname{WTP}(A)$. Then the $R(A)$ is estimated for each subject and the median is calculated.

\section{Results}

\subsection{Sample Characteristics}

The socio-demographic characteristics of the samples can be seen in Table 4. Seven subjects were excluded as they were not willing to pay anything in any of the four WTP questions and gave the reason that, "the government should provide all these treatments free of charge". This was interpreted as a protest response. The final number of observations was 813 . Samples were representative of the Spanish adult general population in terms of age and sex. In terms of education our sample has more subjects with Primary and less with Secondary education than the Spanish general population. Income level is also lower.

\section{[INSERT TABLE 4 ABOUT HERE]}

\subsection{WTP results}

The results of the WTP questions can be seen in Table 5. In all six cases WTP for the 18 months scenario is higher than for the 6 months scenario (differences significant at the $1 \%$ level with t-test and Wilcoxon). The main results are as follows:

\section{[INSERT TABLE 5 ABOUT HERE]}

1. Mean WTP for EoL-LE treatments is higher than for T-QoL treatments. However, it is not clear (from Survey 1 ) if it is because the situation is EoL or if it is because people are willing to pay more for life extensions than for quality of life improvements. It is notable that although mean WTP was higher for EoL treatments the percentage of people that were not willing to pay anything was higher for EoL- 
LE than for T-QoL treatments. This implies that society is split into two very different groups in relation to EoL-LE treatments, namely, there is a reasonably large proportion of subjects who do not give too much value to a short life extension but those who do are willing to pay quite a lot $A$ similar result was observed in Donaldson et al (2010). When compared to T-QoL responses EoL have a much higher standard deviation.

2. WTP for EoL-P treatments is higher than for T-QoL treatments. Again, more people were not willing to pay anything for the EoL treatment in relation to T-QoL. However, the proportion of people not willing to pay was lower than with EoL-LE. Surveys 1 and 2 together suggest that WTP for EoL treatments is higher than for temporary health problems.

3. WTP for EoL-P treatments is higher than for EoL-LE treatments. This would imply that a similar or higher cost per QALY threshold should be applied to quality of life enhancing treatments (such as palliative care) as that applied to life-extending EoL drugs.

Finally, it could be thought that subjects gave very high WTP for EoL treatments because the opportunity cost of money near death is very small. However, this does not seem to be the case since a very low percentage of subjects showed extremely high WTP, e.g. $100.000 €$ or more (Table 5).

\subsection{PTO results}

The picture that emerges from the analysis of PTO data is very similar to that from WTP, at least at the ordinal level. The summary of these results can be viewed in Table 6 .

\section{[INSERT TABLE 6 ABOUT HERE]}

1. T-QoL vs EoL-LE (columns 2 and 5). More people chose the EoL-LE over the T-QoL patients, as was the case with WTP. If WTP and PTO are compared using the same method of aggregation ("ratio of means" and "median of ratios") it can be observed (Tables 5 and 6 ) that the picture given by both methods is not very different. For PTO the ratios are between 1.14-1.5 and for WTP between 1.3-2.0. In both WTP and PTO ratios increase with duration (except for PTO median of ratios), implying that EoL-LE becomes more attractive in relation to temporary health gains when the duration of the life extension increases. The abovementioned idea that society splits in two different groups is confirmed even more clearly by PTO results. This can be observed looking at the number of subjects with extreme preferences, that is, those who say that one patient of the most preferred type is equivalent to 1000 or more patients of the other group. About one out of four subjects $(25.9 \%=11.7 \%+14.2 \%)$ expressed these sort of preferences. These percentages are very similar regardless of whether 
respondents preferred EoL-LE or T-QoL. particularly with the 6 months duration. For the 18 months duration, fewer respondents expressed extreme preferences for T-QoL and the opposite happened with EoL-LE which shows that increasing life extension had an influence on preferences, as might be expected.

2. T-QoL vs EoL-P (columns 3 and 6). EoL-P treatments receive extra weight in relation to Temporary health problems. However, the ratios are more extreme with PTO than with WTP. The ratio of means is around 3.30 in PTO and around 1.8 in WTP. The median of ratios with PTO (18.0 and 15.0 for the six months and 18 months durations, respectively) is much more extreme than any ratio produced by WTP. These differences can be explained by the fact that in WTP questions people have a budget constraint whis is not relevant in responding to PTO questions. It could also be explained by the fact that in PTO the comparison is conducted 'head to head' while in WTP the comparison is between values elicited in two separate questions. This may enhace differences between groups in PTO. The total percentage of extreme responses is much as before but in this case it is almost exclusively concentrated on those who prioritize EoL-P $(23.7 \%$ vs $3 \%$ for 6 months).

3. EoL-LE vs EoL-P (columns 4 and 7 ) EoL-P receives higher weight than EoL-LE when both contexts are compared directly. However, the ratios obtained with the direct comparisons are much smaller than the ratios obtained in Surveys 1 and 2 . That is, when they are compared indirectly (through T-QoL) it seems that EoL-P receives a much higher weight than EoL-LE. When they are compared directly, the result is much more in line with the ratios observed in WTP, demonstrating the importance of comparing options directly. Another interesting result is that when both EoL treatments are compared directly, there are very few extreme responses. This shows that there is something very different in the comparison between our EoL scenarios and the temporary health gains that generates a large number of extreme responses (about 1 in 4) that disappear when both EoL treatments are compared directly.

\subsection{Inconsistencies}

The picture presented by the findings above appears to be quite consistent but inconsistencies were observed at the individual level. For example, in WTP questions many people gave the same answer irrespective of the duration of health gains (6 vs. 18 months). This happened in $22.7 \%$ of the 
valuations in the Temporary health problem scenario, in $41.8 \%$ of the subjects valuing the Life Extending treatment and in $34.3 \%$ of the cases in the Palliative care context.

\section{[INSERT TABLE 7 ABOUT HERE]}

Another type of inconsistency emerges when WTP and PTO responses are compared at an individual level. As can be seen in Table 7, there were people who favoured one option in PTO but they were willing to pay less for this option. This may not represent an inconsistency since the perspectives were different (individual vs. social), and it is clear that social preferences could incorporate considerations that are not included in individual WTP questions. However, another (additional rather than competing) possible explanation of these "inconsistencies" is imprecision and error. Given that these kinds of questions are complicated and preferences can be imprecise it is likely that responses are subject to some degree of error. On closer examination of the preference reversals between WTP and PTO responses in these results we observe that they were not random. Those subjects who were in the "minority" in PTO or in WTP (which emerged as Option A in both surveys) produced more inconsistencies. For example, in Surveys 1 and 2 the less preferred option is the Temporary health problem. In Survey 3, the less preferred option is EoL-LE. Concentrating on the choices when the duration is 6 months (for 18 months the picture is basically the same), if those who chose Option $A$ in Survey $1(n=107)$, in Survey $2(n=40)$ and in Survey $3(n=124)$ are added, this gives a total of 271 subjects choosing option A (the minority option). Of those subjects, a total of 108 (39.9\%) reversed their preferences in WTP, that is, they were willing to pay more for Option B. However, among those who chose Option B (the majority option) in PTO $(n=542)$ only $14.8 \%$ reversed their preferences in WTP. It is the same with WTP. A total of 175 were willing to pay more for Option A and 459 were willing to pay more for Option B. Among those who were prepared to pay more for Option A (the minority option), 80 (45.7\%) reversed their preferences in PTO. This only happened in $108(23.5 \%)$ of those subjects who were willing to pay more for Option B (the majority option). If the explanation for the discrepancy between WTP and PTO were some kind of discrepancy between individual and social values we might expect these reversals to be similar in both groups (majority and minority). However, asymmetry is justified if it is assumed that preferences are stochastic, that is, subject to error/noise, given the difficulty of the task. If this interpretation is correct, the ratios of the relative benefit of one option against the other are biased downwards in all cases. That is, the "true" weight for EoL treatments might be higher than that reflected in the means and medians estimated. 


\section{Discussion}

The evidence that this paper presents suggests that: a) QALYs gained at the end of life receive a greater weight than QALYs gained from alleviating temporary health problems, and b) Palliative care receives even greater weight than (short) life extensions at the end of life. It thus seems that the main reason for the extra weight of EoL treatments is not only that QALYs obtained from quality of life improvements are different from QALYs obtained from increasing life expectancy, as has been suggested in the literature (Mason, Jones-Lee \& Donaldson, 2009). Rather, this extra weight seems to be related to the proximity to death per se. In other words, people give an extra value to whatever can be done (life extending or not) for patients in the last stages of their lives.

Setting our work in the context of previous literature, our results are more in line with those Donaldson (2010) than with Linley and Hughes (2012) and Shah, et al. (2012). Our study does not support one potential explanation for different results in previous research, namely, the perspective, since findings were similar from the individual (WTP) and the social (PTO) perspective at least at the ordinal level. We can think of at least two other reasons for the differences between previous findings: the elicitation method and the comparisons conducted. First, there is evidence that the elicitation method may, in itself, generate conflicting results. In a previous study Baker et al. (2010) observed that elicitation method had a decisive effect. Using discrete choice experiments (DCE) they did not observe any kind of weights for QALYs while the same subjects discriminated between patients according to age and severity with PTO. One explanation for the difference in results between our study and the study by Shah et al. (2012) may be their use of DCE and our use of PTO methods. It could be that DCE produces results more in line with QALY maximization as in Baker et al. (2010). The second explanation lies in the different framings used between studies. Linley and Hughes (2012) observe "only $34 \%$ of respondents favoured prioritising patients with a reduced life expectancy in the absence of any other differences" and conclude that this result does not support any special consideration for EoL treatments. However, this conclusion comes from a question where subjects were asked to discriminate between patients with very short life expectancy (1.5 and 5 years). Respondents to our surveys were presented with EoL and temporary health problems. This is also the case in Shah, et al. (2012) since their maximum life expectancy without treatment is 5 years. In our case, life expectancy was very different for these two groups since in one of the groups (temporary health problems) the health problem did not affect life expectancy. For this reason, our results may be 
regarded as complementary (rather than contradictory) to the results reported by Linley and Hughes which are based on EoL weights elicited in a different context. This shows the importance of clearly defining the types of comparisons conducted in the survey. So when claims are made that research findings (do or do not) support weights for EoL the relevant question is, compared to what? We would interpret Linley and Hughes' results as implying that maybe we should not discriminate between two groups of patients whose life expectancy is reduced, even if it is different. Our results, however, suggest that when EoL is compared with temporary conditions, involving a non-trivial loss of quality of life $(50 \%)$, we find that EoL treatments are given priority. The relevance of framing is also suggested comparing the results of a small scale study (Shah, Tsuchiya \& Wailoo, 2013) with ours. Shah et al. (2013) used some scenarios (their scenarios 4 and 5) that are similar to our comparison between EoL-LE and EoL-QoL. Their subjects prioritized improving quality of life above life expectancy for patients with a 12 months life expectancy (58\% vs $22 \%$ with $20 \%$ being indifferent between both options). This coincides with our results.

Our data suggest that some extra weight could be reasonable for QALYs gained at the end of life in relation to QALYs gained treating temporary health problems. Perhaps more significant, though, is our finding that improvements in quality of life at the end of life (e.g. through palliative care) could be valued even more highly than life extensions. This result is very consistent. It can be observed in indirect comparisons (linking the results of Surveys 1 and 2) and direct comparisons (Survey 3), and in both WTP values and PTO weights. We interpret this as implying that people may prioritize having a "good death" over marginal extensions in life expectancy. This could be relevant for the evaluation of EoL care and treatments. NICE supplementary advice on EoL, for example, states that it is "technically more accurate....to include only the QALYS gained through extension of life and not the QALYs gained through improved quality of life during any extended 'progression free' period". Our study suggests that this way of evaluating EoL medical treatments may not correspond with social preferences. If anything, QALYs gained through improvements in quality of life at the EoL should receive a higher weight. Cancer drugs for people at the end of life could receive an extra weight if they reduce toxicity and therefore symptoms, even if they do not extend life. This may help to improve the perceived benefits of palliative treatments that have often been considered not cost-effective given the benefits they provide are of short duration (Hughes, 2005). If this is the case, quality of life measurement is of paramount importance in the evaluation of cancer drugs. A review of 110 
evaluations of cancer treatments (Tengs, 2004) found that quality of life did not make much difference in resource allocation decisions. This is very surprising since such treatments can have serious side effects. This result might be explained (Garau et al., 2011) by limitations in the QALY model (e.g. failure of the constant proportional trade-off assumption) or, at least, in the way that quality of life is measured (e.g. using an instrument, such as the EuroQol, that may not be sensitive enough). Our results reinforce the need to improve methods to measure quality of life when evaluating end of life technologies such as drugs for advanced cancer.

Inevitably there are limitations to this study. First of all, we are aware of that the tasks in the questionnaires may have presented difficulties for respondents. It is possible that some of the issues raised in the survey have been misunderstood by some of the participants. This possibility is intrinsic with this type of questions. However, we think that the patterns in the data show a good degree of coherence suggesting that subjects have understood the scenarios - at least to reasonable extent and allowing for error. Secondly, we presented quality of life using percentages, a method that has been previously used in the literature (Shah, et al., 2012; Dolan \& Tsuchiya, 2009), but it is possible that using a different framing results would have changed, It would be interesting to see, in future research, what would happen if quality of life were described in a less abstract manner (e.g. by describing symptoms). In terms of the elicitation procedure, although the tables used both in WTP and PTO questions, may have mitigated starting point bias, it might cause range bias problems. Nevertheless, since our aim is to compare between different types of health gains, relative rather than absolute values matter. Another limitation of this study is that it does not provide information on the comparison between treatments for End of Life patients and those with chronic illnesses. Given the large amount of resources spent in chronic conditions this seems a very important case to analyse. However, incorporating chronic illness scenarios is challenging, within this study design, since the size of the QALY gain is held constant across scenarios. The number of QALYs provided by EoL treatments is, by definition, relatively small and most (effective) treatments for chronic conditions would produce more QALYs. Our study also raises new questions that should be pursued in future research. One is the relationship between EoL weights and severity weights. It has been suggested (Cookson, 2013) that EoL weights could be a special case of severity weights. If so, EoL weights could be included within a general weighting system for QALYs. However, given that there is no unanimity about how severity should be measured (e.g., using fair innings (Wiliams, 1997), quality of 
life without treatment (Nord et al, 1999; Nord, 2005), proportional shortfall (Stalk, 2004; Stalk et al 2005)) showing that EoL weights are a special case of a more general phenomenon involves collecting a significant amount of empirical evidence. In the meantime, our results suggest that some extra weight for EoL treatments might be justified. Finally, our results may to some extent be different for different situations. For example, preferences between EoL-QoL and EoL-LE could be different for different levels of quality of life (e.g. $80 \%$ instead of $50 \%$ ). Future research should try to clarify these issues.

In summary, we have found some support for policies which give extra weight to QALYs gained at the end of life when they are compared with treatments for temporary health problems that produce the same number of QALYs. Our study also suggests that the main reason for this weight is not that QALYs obtained by increasing life expectancy are more valued than those obtained by improving quality of life. We have shown that improvements in quality of life themselves -without any gain in life extension- are more valued when they occur at the end of life. In fact, our results suggest that these quality of life gains might be even more important than life extension. This has consequences for the way that public agencies evaluate medicines. 


\section{References}

Baker, R., Bateman, I., Donaldson, C., Jones-Lee, M., Lancsar, E., Loomes, G. ... Wildman, J. (2010). Weighting and valuing quality-adjusted life-years using stated preference methods:

Preliminary results from the social value of a QALY project. Health Technology Assessment, 14(27), 1-162. doi: 10.3310/hta14270.

Chilton, S., Covey, J., Hopkins, L., Jones-Lee, M., Loomes, G., Pidgeon, N., \& Spencer, A. (2002). Public perceptions of risk and preference-based values of safety. Journal of Risk and Uncertainty, 25(3), 211-232.

Cookson R. (2013) Can the NICE "End-of-Life premium be given a coherent ethical justification? Journal of Health Politics, Policy and Law, 38 (6), 1129-1148.

Culyer, A., McCabe, C., Briggs, A., Claxton, K., Buxton, M., Akehurst, R., ... Brazier, J. (2007). Searching for a threshold, not setting one: The role of the national institute for health and clinical excellence. Journal of Health Services Research and Policy, 12, 56-58. doi:

$10.1258 / 135581907779497567$.

Department of Health, Medicines, Pharmacy \& Industry Group (2011). A new value-based approach to the pricing of branded medicines. Government response to consultation. Retrieved from http://webarchive.nationalarchives.gov.uk/20130107105354/http://www.dh.gov.uk/prod consum dh/gr oups/dh digitalassets/documents/digitalasset/dh 128404.pdf [Accessed May 16, 2013].

Dolan, P., \& Tsuchiya, A. (2009) The social welfare function and individual responsibility: Some theoretical issues and empirical evidence. Journal of Health Economics, 28, 210-220.

Donaldson, C. (Co-ordinator). (2010) European value of a quality adjusted life year. European Commission. SP5A-CT-2007-044172. Sixth Framework Programme. Retrieved from http://research.ncl.ac.uk/eurovaq/EuroVaQ Final Publishable Report and Appendices.pdf. [Accessed May 15. 2013]

Garau, M., Shah, K.K., Mason, A.R., Wang, Q., Towse, A., \& Drummond, M.F. (2011) Using qalys in cancer: A review of the methodological limitations. Pharmacoeconomics, 29, 673-685. doi: $10.2165 / 11588250-000000000-00000$ 
Hughes J (2005), Palliative Care and the QALY problem Health Care Analysis 13 (4) 289-301. IOM (Institute of Medicine) (2009). Assessing and improving value in cancer care: Workshop summary. Washington, D.C.: The National Academies Press.

Keeney, R., \& Raiffa, H. (1976). Decisions with multiple objectives. New York: Wiley. Linley, W.G., \&Hughes, D.A. (2012), Societal views on NICE, cancer drugs fund and value-based pricing criteria for prioritising medicines: a cross-sectional survey of 4118 adults in great britain. Health Economics. Advance online publication. doi:10.1002/hec.2872.

Loomes, G. (2010). Modeling choice and valuation in decision experiments. Psychological Review, $117,902-924$

Mason, H., Jones-Lee, M., \& Donaldson, C. (2009). Modelling the monetary value of a QALY: A new approach based on UK data. Health Economics, 18, 933-950. doi: 10.1002/hec.1416.

Maynard, A., \& Bloor, K. (2009). NICE wobbles. Journal of the Royal Society of Medicine, 102, 212213. doi: $10.1258 / \mathrm{jrsm} .2009 .09 \mathrm{k} 031$.

Morris, J., \& Perez, D. (2000). Willingness to pay for new chemotherapy for advanced ovarian cancer. New Zealand Medical Journal,113, 143-146. Retrieved from http://journal.nzma.org.nz/journal/1131108/2180/content.pdf.

Nadler, E., Broderick, W.C., Zarotsky, V., \& Kim, J. (2009). How do medical and pharmacy directors perceive the value of new cancer drugs? Drug Benefit Trends, 21, 120-130.

Nadler, E., Eckert, B., \& Neumann, P.J. (2006). Do oncologists believe new cancer drugs offer good value? Oncologist, 11, 90-95. doi:10.1634/theoncologist.

National Institute for Clinical Excellence. (2008). Appraising end of life medicines: Consultation document. Retrieved from http://www.nice.org.uk/media/26E/43/Endoflifemedicines.pdf [Accessed May 16, 2013] National Institute for Clinical Excellence. (2009). Update report on the application of the 'End-of- Life' Supplementary Advice in health technology appraisals.2009. Retrieved from http://www.nice.org.uk/media/835/8E/ITEM7EndOfLifeTreatments.pdf [Accessed May 16, 2013] Nord, E. (2005). Concerns for the worse off: Fair innings versus severity. Soc Sci Med, 60(2), 257-63. Nord, E., Pinto, J.L., Richardson, J., Menzel, P., \& Ubel, P. (1999). Incorporating societal concerns for fairness in numerical valuations of health programmes. Health Economics, 8, 25-39. doi: 10.1002/(SICI)1099-1050(199902)8:1<25::AID-HEC398>3.0.CO;2-H 
Office of Fair Trading. (2007). The Pharmaceutical Price Regulation Scheme. An OFT Market Study. Retrieved form: http://www.oft.gov.uk/OFTwork/markets-work/pprs [Accessed May 15, 2013] Raftery, J. (2009). Should NICE's threshold range for cost per QALY be raised? No. British Medical Journal, 338, b185. doi: 10.1136/bmj.b185

Shafir, E.B., Osherson, D.N., \& Smith, E.E. (1989). An advantage model of choice. Journal of Behavioral Decision Making, 2, 1-23. doi: 10.1002/bdm.3960020102

Shah, K.K., Tsuchiya, A., Hole, A.R., \& Wailoo, A.J. (2012). Valuing health at the end of life: A stated preference discrete choice experiment. NICE Decision Support Unit Report, Dec 2012. Retrieved from http://www.nicedsu.org.uk/DSU\%20End\%20of\%20Life\%20full\%20report\%20\%20version\%203\%20_Dec\%202012_.pdf.

Shah, Koonal K, Aki Tsuchiya, \& Wailoo, A.J. (2013). Valuing health at the end of life: An empirical study of public preferences. Eur J Health Econ doi:10.1007/s10198-013-0482-3

Simonson, I., \& Drolet, A. (2004). Anchoring Effects on Consumers' Willingness-to-Pay and Willingness-to-Accept. Journal of Consumer Research, 31, 681-690. doi: 10.1086/425103.

Stolk EA, van Donselaar G, Brouwer WB, \& Busschbach JJ. (2004). Reconciliation of economic concerns and health policy: illustration of an equity adjustment procedure using proportional shortfall. Pharmacoeconomics, 22(17):1097-107.

Stolk, E. A., Pickee, S. J., Ament, A. H., \& Busschbach, J. J. (2005). Equity in health care prioritisation: An empirical inquiry into social value. Health Policy, 74(3), 343-55.

Tengs, T.O. (2004). Cost-Effectiveness versus cost--utility analysis of interventions for cancer: Does adjusting for health-related quality of life really matter? Value in Health, 7, 70-78. doi: 10.1111/j.15244733.2004.71246.x.

Towse, A. (2009) Should NICE's threshold range for cost per QALY be raised? Yes. British Medical Journal, 338, b181. doi: 10.1136/bmj.b181.

Williams, A. (1997). Intergenerational equity: An exploration of the'fair innings' argument. Health Economics, 6(2), 117-132. 


\section{APPENDIX: FRAMING OF QUESTIONS}

\section{WILLINGNESS TO PAY}

\subsection{Scenarios 1-2: End of life, life extending.}

"Imagine that you are diagnosed with a very severe illness. Doctors tell you that in a few days your health state will deteriorate and your health related quality of life will be 50\% (remember that 100\% health is the health state of somebody without health problems) for 3 months. After these months you would die. That is, it is a terminal illness.

The doctor tells you that there is a treatment which might extend your life for 6 additional months with the same health related quality of life of 50\%. This treatment only works in $10 \%$ of patients (10 out of 100 patients). For this reason, 90 out of 100 will not improve at all and their life expectancy would remain at 3 months."'”

"Assume that the government does not cover 100\% of the cost of the medicine. If you want to have the medicine you have to pay something. If you had to pay something for the medicine (say $5 €$ ) would you pay this amount of money in order to receive treatment?

Those who said that they were willing to pay $5 €$ were asked how much they would be willing to pay. They were asked

"We would like to know how much more you would be willing to pay for this treatment. To make this task easier for you, we will show you a table with potential costs that this treatment could have for you. This is the total cost that treatment would have for you, that is, the cost of the full six months"

They were shown the next table where they had to tick "yes" or "no" in each of the monetary amounts presented.

\begin{tabular}{|c|c|c|c|c|c|c|c|c|}
\hline $5 €$ & Si & No & $500 €$ & $\mathrm{OSi}^{\mathrm{Si}}$ & No & $4000 €$ & $\mathrm{OSi}^{\mathrm{Si}}$ & No \\
\hline $10 €$ & Si & No & $700 €$ & $\mathrm{Si}$ & No & $5000 €$ & $\mathrm{OSi}^{\mathrm{Si}}$ & ONo \\
\hline $20 €$ & $\mathrm{Si}$ & No & $1000 €$ & $\mathrm{Si}$ & No & $7000 €$ & $\mathrm{OSi}^{\mathrm{Si}}$ & ONo \\
\hline $50 €$ & $\mathrm{Si}$ & ONo & $1500 €$ & $\mathrm{Si}$ & ONo & $10000 €$ & Si & ONo \\
\hline $100 €$ & Si & No & $2000 €$ & $\mathrm{Si}$ & No & $25000 €$ & Si & ONo \\
\hline $200 €$ & $\mathrm{Si}$ & No & $2500 €$ & $\mathrm{SSi}$ & No & $\begin{array}{r}\text { Mas de } \\
25000 €\end{array}$ & Si & ONo \\
\hline $300 €$ & Si & No & $3000 €$ & $\mathrm{Si}$ & No & & & \\
\hline
\end{tabular}

Their responses to this table established an interval where the maximum WTP was located. Subjects were then asked for the maximum amount, within that interval, that they were willing to pay. If the respondent said "Yes" to all the figures, then s/he was 
asked "what is the maximum amount of money above $25000 €$ you would be willing to pay?".

\subsection{Scenarios 3-4: End of life, palliative care}

"Imagine that you are diagnosed with a very severe illness. Doctors tell you that in a few days your health state will deteriorate and your health related quality of life will be 30\% for 6 months (remember that 100\% health is the health state of somebody without health problems) . After these months you would die.

The doctor tells you that there is a treatment to improve your quality of life during these 6 months to $80 \%$, that is, you will improve but your health will not be perfect. It is a palliative treatment, as it improves your quality of life during the last stages of your life, but it does not improve your life expectancy which would still be 6 months.

This treatment is only works in 10\% of patients (10 out of 100). For this reason, 90 out of 100 will not improve at all and their health would remain at 30\%."

\subsection{Scenarios 5-6: Temporary health benefit}

"Imagine that you are diagnosed with a disease and you are told that you will spend the next 6 months with a quality of life of 30\% (remember that 100\% health is the health state of somebody without health problems). There is a free treatment for this disease so after 6 months you will be back to 100\%. However, this treatment does not relieve symptoms. So until you recover (6 months) you will experience a quality of life of $30 \%$. The illness is not life threatening. It is, therefore, a temporary health problem.

The doctor tells you that there is a treatment that may relieve symptoms during these 6 months. This treatment can improve your health up to 80\%, that is, it improves your health but it is not perfect. The treatment only works in 10 of 100 patients (1 in 10). Therefore, in 90 out of 100 patients it does not improve health and those patients are left with a health level of 30\%".

\section{PERSON TRADE-OFF}

2.1. Scenario 5 vs. Scenario 1: Temporary health benefit vs. End of life, life extending

"Imagine there are two patients, $A$ and B. Patient $A$ has been diagnosed with a disease and $s /$ he is told that s/he will spend the next six months with a quality of life of $30 \%$ (remember that 100\% health is the health state of somebody without health problems). There is a treatment for this disease so after 6 months (more or less) s/he will be back to $100 \%$. However, this treatment does not relieve symptoms. So until s/he recovers (about 6 months) s/he will experience a quality of life of $30 \%$. The illness is not life threatening. It is, therefore, a temporary health problem.

Patient $B$ has been diagnosed with a terminal health problem. In a few days, his/her health will deteriorate and $s /$ he will have a health state that is $50 \%$ of full health. Once this happens (almost immediately) her life expectancy will be about 3 months. 
There are medical treatments that may improve the health of both patients. In the case of patient $A$, there is a treatment that can alleviate symptom during these 6 months that she needs to recover completely. This treatment can improve his/her health up to $80 \%$, that is, it improves health but it is not perfect. In the case of patient $B$, there is a treatment that will improve his/her life expectancy by 6 months, that is life expectancy increases from 3 to 9 months.

Assume that there is not enough money to provide treatment to both patients and we can only help one of them. If you were the person that had to decide to choose between patient $A$ or patient $B$, who would you choose?

\begin{tabular}{|c|c|c|}
\hline & $\begin{array}{l}\text { Number of } \\
\text { patients }\end{array}$ & Benefit of the treatment \\
\hline PATIENT A & 1 & $\begin{array}{c}\text { Quality of life improves by } 50 \% \text { (from } 30 \% \text { to } \\
80 \% \text { ) for } 6 \text { months }\end{array}$ \\
\hline PATIENT B & 1 & $\begin{array}{c}\text { Increases life expectancy by } 6 \text { months (from } 3 \text { to } \\
9 \text { months) with quality of life at 50\% }\end{array}$ \\
\hline
\end{tabular}

(Assume respondent chooses B)

You said that if we could give medical treatment to one of the two patients you would choose patient B. Now assume that there are two patients like A and with the same money you can provide treatment to one patient like B or two patients like A. That is, you would have to choose between

\begin{tabular}{|c|c|c|}
\hline & $\begin{array}{c}\text { Number of } \\
\text { patients }\end{array}$ & $\begin{array}{c}\text { Benefit of the treatment } \\
\text { PATIENT A }\end{array}$ \\
\hline PATIENT B & 1 & $\begin{array}{c}\text { Quality of life improves by } 50 \% \text { (from } 30 \% \text { to } \\
80 \% \text { ) for } 6 \text { months }\end{array}$ \\
\hline
\end{tabular}

If you were the person that had to decide to choose between patient $B$ or the two patients of type $A$, which would you choose?

If respondent chooses the two type A patients, then this part of the questionnaire ends, and. If respondent chooses patient $B, s /$ he is asked how many patients of type A would balance the choice between give the treatment to them or to patient $B$ :

You said that if we could give only one of the two medical treatments you would choose patient $B$ before treating two patients like A. Notwithstanding, it is very likely that if we increase the number of patients of type A (with a temporary health problem) that could be treated with the same amount of money, there would be a moment in which you might prefer to benefit more patients of type A than a patient of type B (at an end-of-life situation). Though we know that this is a very difficult question, we would like you to figure out when do you think you would choose the patients of type A. We would try to make this task easier by showing you a table in which the number of patients of type $A$ 
who could be treated changes.

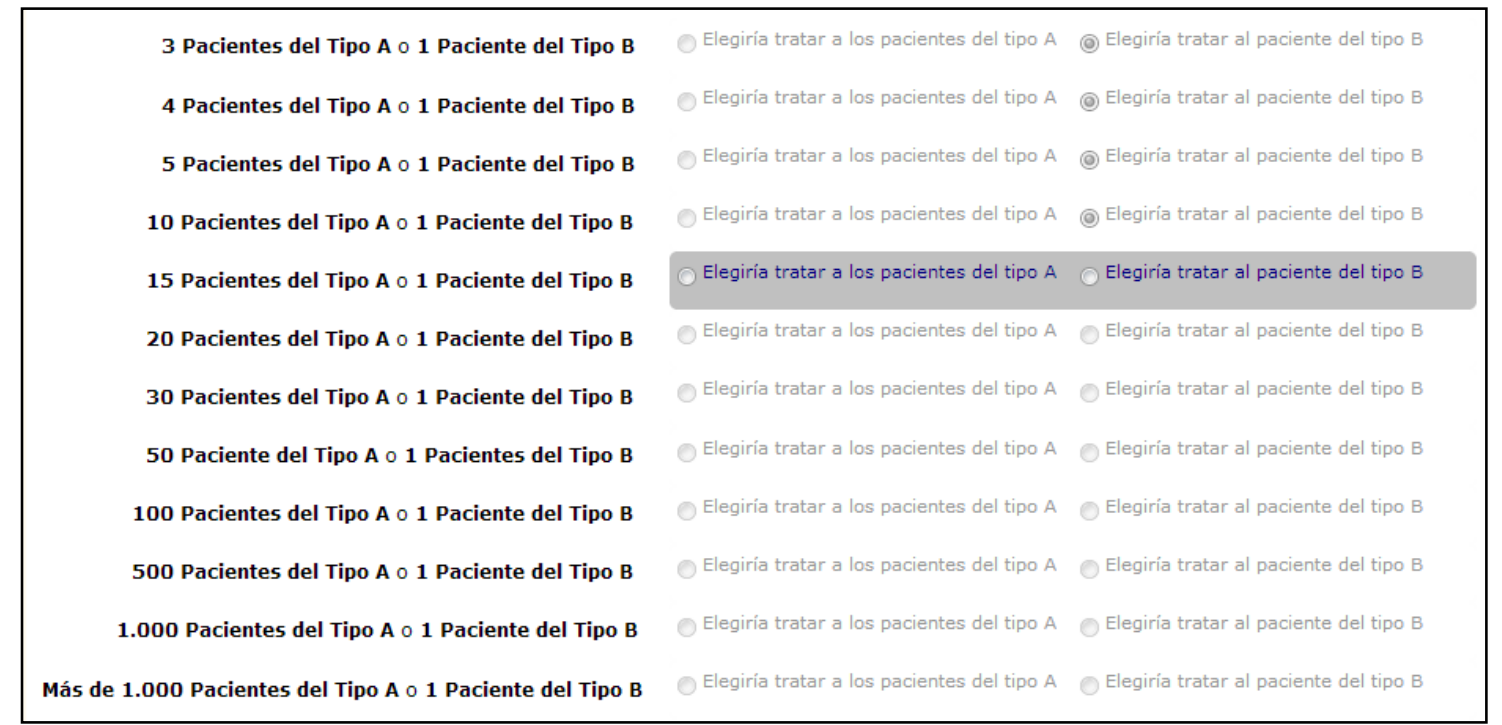

2.2. Scenario 5 vs. Scenario 3: Temporary health benefit vs. End of life, palliative care

"Imagine there are two patients, $A$ and B. Patient $A$ has been diagnosed with a disease and $s /$ he is told that s/he will spend the next six months with a quality of life of $30 \%$ (remember that 100\% health is the health state of somebody without health problems). There is a treatment for this disease so after 6 months (more or less) s/he will be back to $100 \%$. However, this treatment does not relieve symptoms. So until s/he recovers (about 6 months) s/he will experience a quality of life of $30 \%$. The illness is not life threatening. It is, therefore, a temporary health problem.

Patient $B$ has been diagnosed with a terminal health problem. in a few days his/her health state will deteriorate and s/he health related quality of life will be 30\% for 6 months (remember that 100\% health is the health state of somebody without health problems). After these months s/he would die.

There are medical treatments that may improve the health of both patients. In the case of patient $A$, there is a treatment that can alleviate symptoms during these 6 months that she needs to recover completely. This treatment can improve her health up to $80 \%$, that is, it improves health but it is not perfect. In the case of patient $B$, there is a treatment that will improve hi/her quality of life during these 6 months to 80. It is a palliative treatment, as it improves quality of life during the last stages of life, but it does not improve your life expectancy which would still be 6 months. 
Table 1. Scenarios used in the surveys.

\begin{tabular}{|c|c|c|c|}
\hline & Without treatment & With treatment (1) & QALY Health gain (2) \\
\hline $\begin{array}{l}\text { Scenario 1. End of life, life extending } \\
\text { treatment (EoL-LE), } 6 \text { months. }\end{array}$ & $\begin{array}{l}\text { Life expectancy: } 3 \text { months } \\
\text { Quality of life: } 50 \% \text { of normal health }\end{array}$ & $\begin{array}{l}\text { Life expectancy: } 9 \text { months } \\
\text { Quality of life: } 50 \% \text { of normal health }\end{array}$ & $\begin{array}{c}6 \text { months life extension at } 50 \% \\
(0.25 \text { QALY })\end{array}$ \\
\hline $\begin{array}{l}\text { Scenario 2. End of life, life extending } \\
\text { treatment (EoL-LE), } 18 \text { months. }\end{array}$ & $\begin{array}{l}\text { Life expectancy: } 3 \text { months } \\
\text { Quality of life: } 50 \% \text { of normal health }\end{array}$ & $\begin{array}{l}\text { Life expectancy: } 21 \text { months } \\
\text { Quality of life: } 50 \% \text { of normal health }\end{array}$ & $\begin{array}{c}18 \text { months life extension at } 50 \% \\
\text { (0.75 QALY) }\end{array}$ \\
\hline $\begin{array}{l}\text { Scenario 4. End of life, palliative care } \\
\text { (EoL-QoL), } 18 \text { months }\end{array}$ & $\begin{array}{c}\text { Life expectancy: } 18 \text { months } \\
\text { Quality of life: } 30 \% \text { of normal health }\end{array}$ & $\begin{array}{l}\text { Life expectancy: } 18 \text { months } \\
\text { Quality of life: } 80 \% \text { of normal health }\end{array}$ & $\begin{array}{l}50 \% \text { QoL improvement for } 18 \\
\text { months ( } 0.75 \text { QALY) }\end{array}$ \\
\hline $\begin{array}{l}\text { Scenario } 5 \text {. Temporary health benefit } \\
\text { (T-QoL), } 6 \text { months }\end{array}$ & $\begin{array}{l}\text { Life expectancy: not affected } \\
\text { Quality of life: } 30 \% \text { of normal health } \\
\text { during } 6 \text { months; then normal health. }\end{array}$ & $\begin{array}{l}\text { Life expectancy: not affected } \\
\text { Quality of life: } 80 \% \text { of normal health } \\
\text { during } 6 \text { months; then normal health. }\end{array}$ & $\begin{array}{c}50 \% \text { QoL improvement for } 6 \text { months } \\
\text { (0.25 QALY) }\end{array}$ \\
\hline
\end{tabular}


Table 2. Structure of the surveys.

\begin{tabular}{|c|c|c|c|c|}
\hline \multicolumn{5}{|c|}{ Introduction } \\
\hline & & Survey 1 & Survey 2 & Survey 3 \\
\hline \multirow{2}{*}{$\begin{array}{l}\text { Part } 1 \\
\text { WTP(A) }\end{array}$} & $\begin{array}{c}\text { Question } \\
1\end{array}$ & $\begin{array}{l}\text { T-QoL, } 6 \text { months } \\
\text { (Scenario 5) }\end{array}$ & $\begin{array}{l}\text { T-QoL, } 6 \text { months } \\
\text { (Scenario 5) }\end{array}$ & $\begin{array}{l}\text { EoL-P, } 6 \text { months } \\
\quad \text { (Scenario 3) }\end{array}$ \\
\hline & $\begin{array}{c}\text { Question } \\
2\end{array}$ & $\begin{array}{l}\text { T-QoL, } 18 \text { months } \\
\text { (Scenario 6) }\end{array}$ & $\begin{array}{l}\text { T-QoL, } 18 \text { months } \\
\text { (Scenario 6) }\end{array}$ & $\begin{array}{l}\text { EoL-P, } 18 \text { months } \\
\quad(\text { Scenario } 4)\end{array}$ \\
\hline \multirow{2}{*}{$\begin{array}{l}\text { Part 2 } \\
\text { (PTO) }\end{array}$} & $\begin{array}{c}\text { Question } \\
3\end{array}$ & $\begin{array}{l}\text { T-QoL vs. EoL-LE, } \\
6 \text { months } \\
\text { (Scenarios } 5 \text { vs. } 1 \text { ) }\end{array}$ & $\begin{array}{l}\text { T-QoL vs. EoL-P, } \\
6 \text { months } \\
\text { (Scenarios } 5 \text { vs. } 3 \text { ) }\end{array}$ & $\begin{array}{l}\text { EoL-P vs. Eo-/LE, } \\
6 \text { months } \\
\text { (Scenarios } 3 \text { vs. 1) }\end{array}$ \\
\hline & $\begin{array}{c}\text { Question } \\
\quad 4\end{array}$ & $\begin{array}{l}\text { T-QoL vs. EoL-LE, } \\
18 \text { months } \\
\text { (Scenarios } 6 \text { vs. 2) }\end{array}$ & $\begin{array}{l}\text { T-QoL vs. EoL-P, } \\
18 \text { months } \\
\text { (Scenarios } 6 \text { vs. } 4 \text { ) }\end{array}$ & $\begin{array}{l}\text { EoL-P vs. Eo-/LE, } \\
18 \text { months } \\
\text { (Scenarios } 4 \text { vs. 2) }\end{array}$ \\
\hline \multirow{2}{*}{$\begin{array}{l}\text { Part } 3 \\
\text { WTP(B) }\end{array}$} & $\begin{array}{c}\text { Question } \\
5\end{array}$ & $\begin{array}{l}\text { EoL-LE, } 6 \text { months } \\
\quad \text { (Scenario 1) }\end{array}$ & $\begin{array}{l}\text { EoL-P, } 6 \text { months } \\
\text { (Scenario 3) }\end{array}$ & $\begin{array}{l}\text { EoL-LE, } 6 \text { months } \\
\quad \text { (Scenario 1) }\end{array}$ \\
\hline & $\begin{array}{c}\text { Question } \\
6\end{array}$ & $\begin{array}{l}\text { EoL-LE, } 18 \text { months } \\
\text { (Scenario 2) }\end{array}$ & $\begin{array}{l}\text { EoL-P, } 18 \text { months } \\
\text { (Scenario } 4)\end{array}$ & $\begin{array}{l}\text { EoL-LE, } 18 \text { months } \\
\text { (Scenario 2) }\end{array}$ \\
\hline
\end{tabular}

WTP: Willingness to pay. PTO: Person trade-off. T-QoL: Temporary health gain. EoL-P:

Palliative care. EoL-LE: Life extending treatment. $A$ and $B$ refer to the scenario which is valued in the first and the second place, respectively, in each survey. 
Table 3. An example of the two methods used to aggregate person trade-off responses.

\begin{tabular}{|c|c|c|c|c|c|c|}
\hline \multirow{2}{*}{$\begin{array}{c}\text { Respondent } \\
\text { ID }\end{array}$} & \multicolumn{2}{|c|}{ Raw responses $(*)$} & \multirow{2}{*}{\multicolumn{2}{|c|}{ Ratio of Means (RoM) }} & \multicolumn{2}{|c|}{ Median of ratios } \\
\hline & $A$ & $B$ & & & \multirow{2}{*}{$\begin{array}{c}\text { A based } \\
4.00\end{array}$} & \multirow{2}{*}{$\frac{\text { B based }}{0.25}$} \\
\hline 1 & 1 & 4 & 1.00 & 0.25 & & \\
\hline 2 & 1 & 10 & 1.00 & 0.10 & 10.00 & 0.10 \\
\hline 3 & 1 & 20 & 1.00 & 0.05 & 20.00 & 0.05 \\
\hline 4 & 20 & 1 & 0.05 & 1.00 & 0.05 & 20.00 \\
\hline \multirow[t]{4}{*}{5} & 3 & 1 & 0.33 & 1.00 & 0.33 & 3.00 \\
\hline & & & Mean $=0.68$ & Mean $=0.48$ & & \\
\hline & & & $\operatorname{RoM}(A / B)$ & 1.41 & 4.00 & 0.25 \\
\hline & & & RoM (B/A) & 0.71 & & \\
\hline
\end{tabular}

$\left.{ }^{*}\right)$ Number $(\mathrm{Ni})$ of patients $A(B)$ which are considered equivalent to 1 patient $B(A)$. 
Table 4. Socio-demographic characteristics of subjects

\begin{tabular}{|l|cccc|c|}
\hline & $\begin{array}{c}\text { Survey 1 } \\
(\mathrm{n}=239)\end{array}$ & $\begin{array}{c}\text { Survey 2 } \\
(\mathrm{n}=232)\end{array}$ & $\begin{array}{c}\text { Survey 3 } \\
(\mathrm{n}=342)\end{array}$ & $\begin{array}{c}\text { Total } \\
(\mathrm{N}=813)\end{array}$ & $\begin{array}{c}\text { Spanish } \\
\text { population } \\
\left({ }^{*}\right)\end{array}$ \\
\hline Male/Female (\%) & $51 / 49$ & $51 / 49$ & $52 / 48$ & $51 / 49$ & $51 / 49$ \\
Mean (SD) age in years & 42.6 & 43.8 & 44.0 & 43.5 & 42.7 \\
Marital status (\%) & $(15.5)$ & $(15.2)$ & $(14.9)$ & $(15.1)$ & $(16.9)$ \\
$\quad$ Married/Cohabiting & 44.8 & 59,5 & 59.1 & 55.0 & 63.1 \\
$\quad$ Single/Divorced/Widow & 55.2 & 40,5 & 40.9 & 45.0 & 36.9 \\
Education level (\%) & & & & & \\
$\quad$ Illiterate/Primary studies & 37.7 & 31.0 & 49.1 & 40.6 & 30.1 \\
Secondary studies & 41.4 & 43.5 & 28.1 & 36.4 & 45.1 \\
$\quad$ University studies & 20.9 & 25.4 & 22.8 & 23.0 & 24.7 \\
Employment status (\%) & & & & & \\
$\quad$ Employed & 51.0 & 59.1 & 56.7 & 55.7 & 48.0 \\
Unemployed & 17.2 & 11.2 & 15.8 & 14.9 & 12.0 \\
Inactive & 31.8 & 29.7 & 27.5 & 29.4 & 40.0 \\
Income level (\%) & & & & & \\
$\quad$ Up to $€ 1,500$ & 82.8 & 55.6 & 63.7 & 67.0 & 52.3 \\
$\quad € 1,501-2,000$ & 10.9 & 17.7 & 20.5 & 16.9 & 17.2 \\
$\quad € 2.001-3,000$ & 5.0 & 14.7 & 14.0 & 11.6 & 19.5 \\
More than $€ 3,000$ & 1.3 & 12.1 & 1.8 & 4.6 & 11.0 \\
\hline
\end{tabular}

$\left({ }^{*}\right)$ Instituto Nacional de Estadística (National Statistics Institute). www.ine.es. 
Table 5. Willingness to Pay (WTP) data

\begin{tabular}{|c|c|c|c|c|c|c|}
\hline & \multicolumn{3}{|c|}{6 months } & \multicolumn{3}{|c|}{18 months } \\
\hline A & T-QoL & T-QoL & EoL-LE & T-QoL & T-QoL & EoL-LE \\
\hline B & EoL-LE & EoL-P & EoL-P & EoL-LE & EoL-P & EoL-P \\
\hline $\begin{array}{l}\text { Mean }(s d) \operatorname{WTP}(A)(€) \\
\text { Mean (sd) WTP(B) (€) }\end{array}$ & $\begin{array}{c}371.1 \\
(726.5) \\
647.2 \\
(1370.6) \\
\end{array}$ & $\begin{array}{c}499.8 \\
(1078.7) \\
1247.3 \\
(2270.9) \\
\end{array}$ & $\begin{array}{c}976.9 \\
(2044.9) \\
1227.9 \\
(2214.1) \\
\end{array}$ & $\begin{array}{c}556.6 \\
(926.4) \\
1239.1 \\
(2524.2) \\
\end{array}$ & $\begin{array}{c}858.0 \\
(1646.0) \\
2083.1 \\
(3339.0) \\
\end{array}$ & $\begin{array}{c}1480.0 \\
(2680.8) \\
1786.9 \\
(2777.0) \\
\end{array}$ \\
\hline$\% \operatorname{WTP}(\mathrm{A})>\operatorname{WTP}(\mathrm{B})$ & 23.4 & 11.2 & 27.2 & 19.2 & 12.1 & 26.9 \\
\hline$\% \operatorname{WTP}(\mathrm{A})=\mathrm{WTP}(\mathrm{B})$ & 19.7 & 14.7 & 28.7 & 14.6 & 9.1 & 33.3 \\
\hline$\%$ WTP $(A)<\operatorname{WTP}(B)$ & 56.9 & 74.1 & 44.2 & 66.2 & 78.8 & 39.8 \\
\hline$\% \operatorname{WTP}(A)=0$ & 11.3 & 6.5 & 17.3 & 6.7 & 1.3 & 15.5 \\
\hline$\% \mathrm{WTP}(\mathrm{B})=0$ & 23.0 & 12.5 & 6.4 & 12.6 & 6.5 & 9.1 \\
\hline$\% \operatorname{WTP}(A) \geq 10000 €$ & 0.0 & 0.0 & 1.8 & 0.0 & 1.3 & 3.5 \\
\hline$\% \mathrm{WTP}(\mathrm{B}) \geq 10000 €$ & 0.4 & 2.6 & 2.0 & 2.1 & 6.0 & 5.3 \\
\hline Mean of ratios $A>B$ & 0.62 & 0.51 & 0.71 & 0.54 & 0.49 & 0.76 \\
\hline Mean of ratios $B>A$ & 0.80 & 0.91 & 0.86 & 0.85 & 0.92 & 0.89 \\
\hline Ratio of means & 1.29 & 1.78 & 1.22 & 1.57 & 1.86 & 1.17 \\
\hline Median of ratios $(A=1)$ & 1.3 & 2.0 & 1.0 & 2.0 & 2.1 & 1.0 \\
\hline
\end{tabular}

T-QoL: Temporary health gain. EoL-P: Palliative care. EoL-LE: Life extending treatment.

Differences between mean WTP were always statistically significant at $p<0.01$ with t-test and

Wilcoxon text. A and $B$ refer to the scenario which is valued in the first and the second place,

respectively, in each survey. 
Table 6. Relative values from PTO

\begin{tabular}{|c|c|c|c|c|c|c|}
\hline & \multicolumn{3}{|c|}{6 months } & \multicolumn{3}{c|}{18 months } \\
\hline A & T-QoL & T-QoL & EoL-LE & T-QoL & T-QoL & EoL-LE \\
Eol-LE & EoL-P & EoL-P & $\begin{array}{c}\text { EoL-LE } \\
\text { EoL-P }\end{array}$ & EoL-P \\
\hline Prefer A (\%) & 44.8 & 17.2 & 36.3 & 40.6 & 17.2 & 36.5 \\
1A $\geq 1000 B$ & 11.7 & 3.0 & 0.9 & 7.9 & 3.0 & 0.9 \\
\hline Prefer B (\%) & 55.2 & 82.8 & 63.7 & 59.4 & 82.8 & 63.5 \\
1B $\geq 1000 \mathrm{~A}$ & 14.2 & 23.7 & 4.7 & 18.0 & 21.6 & 4.7 \\
\hline Mean ratio A>B & 0.57 & 0.26 & 0.65 & 0.52 & 0.26 & 0.66 \\
Mean ratio B>A & 0.65 & 0.87 & 0.82 & 0.71 & 0.87 & 0.82 \\
Ratio of means & 1.14 & 3.35 & 1.26 & 1.36 & 3.30 & 1.25 \\
\hline Median of ratios (A=1) & 1.5 & 18.0 & 1.5 & 1.5 & 15.0 & 1.5 \\
\hline
\end{tabular}

T-QoL: Temporary health gain. EoL-P: Palliative care. EoL-LE: Life extending treatment. A and $B$ refer to the scenario which is valued in the first and the second place, respectively, in each survey. 
Table 7. Comparison between WTP and PTO

\begin{tabular}{|c|c|c|c|c|c|c|c|c|}
\hline & \multicolumn{4}{|c|}{6 months } & \multicolumn{4}{c|}{18 months } \\
\hline \multirow{2}{*}{ Chosen option } & A<B & A=B & A>B & Total & A<B & A=B & A $>$ B & Total \\
\hline A (T-QoL) & $\mathbf{4 8}$ & 23 & 36 & 107 & $\mathbf{5 7}$ & 11 & 29 & 97 \\
\hline B (EoL-LE) & 88 & 24 & $\mathbf{2 0}$ & 132 & 101 & 24 & $\mathbf{1 7}$ & 142 \\
\hline Total & 136 & 47 & 56 & 239 & 158 & 35 & 46 & 239 \\
\hline A (T-QoL) & $\mathbf{1 5}$ & 12 & 13 & 40 & $\mathbf{2 0}$ & 8 & 12 & 40 \\
\hline B (EoL-P) & 157 & 22 & $\mathbf{1 3}$ & 192 & 163 & 13 & $\mathbf{1 6}$ & 192 \\
\hline Total & 172 & 34 & 26 & 232 & 183 & 21 & 28 & 232 \\
\hline A (EoL-LE) & $\mathbf{4 5}$ & 33 & 46 & 124 & $\mathbf{4 0}$ & 39 & 46 & 125 \\
\hline B (EoL-P) & 106 & 65 & $\mathbf{4 7}$ & 218 & 96 & 75 & $\mathbf{4 6}$ & 217 \\
\hline Total & 151 & 98 & 93 & 342 & 136 & 114 & 92 & 342 \\
\hline
\end{tabular}

Strong Preference Reversals in bold. 